\title{
We have traveled a long distance and sorted out the mess in the drawers: Metaphors for moving toward the end in psychotherapy
}

\begin{abstract}
Aim: To explore the process of ending in psychotherapy, in particular how clients and therapists are drawing on their notions of improvements for the client and are preparing for the upcoming separation.

Data: The data comes from an intensive process-outcome study at the University of Oslo, Norway. The study includes audio-recording from all sessions and separate post-therapy interviews with clients and therapists. Twelve psychotherapy dyads were selected because they had reached a "good enough" ending. Therapy duration ranged from 7 to 43 months. The number of sessions ranged from 10 to 67.

Method and analysis: A hermeneutical-phenomenological approach analyzed and combined the observational and reflexive data. The analysis was carried out with the use of a method for systematic text condensation and through reflexive dialogues with the material and between the researchers.

Findings and discussion: The language of improvement toward the end of treatment seems to be packed with metaphors conveying both growth in affective and relational management. Metaphors based on travel (how they have moved), cleaning (how they have cleaned up and sorted out things), sensing (how the clients have grown stronger, got their heads above water and see things differently), and the clients' feeling of having received something (gifts or tools) are widely used. Such metaphors are created in the interaction with a mutual sensitivity to their capacity to confirm and regulate affect toward the end. In this sense, the metaphors celebrate accomplishments in a way that exceeds therapy, and the client can keep them to use afterward.
\end{abstract}




\section{We have traveled a long distance and sorted out the mess in the drawers: Metaphors for moving toward the end in psychotherapy}

It is well known that metaphors are an important part of therapeutic communication. Human nature is meaning making, and metaphors are about making sense of experiences. Metaphors can be conceived of as narrative condensations of meaning (Goncalves, Henriques \& Machado, 2004). Meaning is interactive and develops through relational interaction and language representations (Bruner, 1985; 1990), but is far from something purely verbal. They are significant aspects of thought and action as well (Lakoff \& Johnson, 1980). Hester (1967, ref. in Alvesson \& Sköldberg, 2000) points out the sensuous-intuitive or experiential element that comes previous to the verbal formulation of a metaphor. Metaphors are expressions which elucidate similarity in difference (Gadamer, 1989) and which indicate some kind of correspondence between two different phenomena (Alvesson \& Sköldberg, 2000). They are so woven into our daily life that we hardly even notice them. As Goncalves et al. (2004) note, our flexibility as human beings rests on an ability to create multiple meanings. Making metaphors in therapy can be a way of transcending what appears to be fixed meaning and to explore multiple meanings. An active use of metaphors in psychotherapy has been found to strengthen the collaborative relationship between therapist and client, and to help both parties to represent important issues in therapy (Angus, 1996; Angus \& Rennie, 1988, 1989;

Rasmussen \& Angus, 1996). Qualitative analyses of metaphoric expression in psychotherapy have suggested that clients in psychotherapies considered as having good outcome develop a core metaphorical theme related to the most important topics and problem areas in the therapy. On the other hand, clients in psychotherapies considered as less productive use a figurative language to describe external experiences not related to the main topics worked on (Angus, 1996; McMullen, 1989). Furthermore, clients in therapies with good outcome tend to 
use metaphors, both their own and their therapist's, to give meaning to inner and personal experiences during therapy, whereas clients in therapies with bad outcome tend to use metaphors only in the earlier phase of therapy, and mostly to give meaning to and express external experiences (McMullen, 1985).

Ending treatment entails separation and may arise powerful and sometimes negative emotions. This may be feelings associated with loss and separation from people we are emotionally attached to and potentially also feelings of being left and abandoned (Holmes, 2010; Muran, Safran \& Eubanks-Carter, 2010; Salberg, 2010; Schlesinger, 2005). Finding a “good enough” way to end treatment is important to both parties (Hoffman, 1998; Gabbard; 2009; Shane, 2009; Salberg, 2010).

In the process of ending in psychotherapy the therapist and the client will most likely look to what they have accomplished. We wondered how therapist and client may use references for improvement in therapeutic dialog in order to justify to them-selves and each other that they are preparing for termination. When we looked at a series of cases, we discovered that the language of improvement toward the end of "good enough" treatment seems to be packed with metaphors. Subsequent questions were about how they created and used such metaphors. We already knew that when the length of therapy is not agreed at the onset, the right time to end is a matter of negotiation, which seems to rest on a shared ideal of reaching a concerted decision (anonymous ref). From there, we could explore in more detail the accomplishments that the content of actual metaphors conveyed and also the ways in which creating and referring to metaphors seemed to matter for the regulation of affects triggered by the upcoming separation in the context of ending.

We explored, on a case-by-case basis, the use of metaphors in the context of ending in a series of therapeutic dyads. The guiding questions consider how metaphors are introduced, developed, and used in the process of ending; how actual metaphors are able to 
express the co-created lived experience of their psychotherapy; how the metaphors of change and improvement may give space for a range of possible meanings attributed to positive outcomes of psychotherapy; and how the use of metaphors may confirm and regulate the affective tension before the upcoming separation. Empirical answers to such questions could bring nuances to our understanding of what constitutes good psychotherapy outcome.

\section{Method and design}

\section{Data}

The psychotherapy processes were selected from a research project called “An intensive process-outcome study of the interpersonal aspects of psychotherapy” (Rønnestad, 2006) conducted at the University of Oslo, Norway. The assignment of clients and the treatment can be characterized as "therapy as usual” and the length of therapy was not predetermined. We were able to select data from twelve cases that had ended, and we knew that in every case both therapist and client had a fairly positive view on the outcome.

All the clients and therapists lived in or near Oslo, the capital of Norway. Twelve clients (ten women and two men; age range 25-52) and eight therapists (five women and three men; age range 49-68) constituted the sample. Therapy duration ranged from 7 to 43 months. The number of sessions ranged from 10 to 67 . The therapy was conducted in an outpatient setting, and the clients paid a low fee for the consultations. Sessions were weekly at the beginning, but frequency varied during the course of therapy.

The therapists' mean years of individual practice were 30 years (range 15-35). Seven of the therapists were licensed clinical psychologists, and one was a medical doctor, a specialist in psychiatry. All the therapists based their work on several therapy theories.

All twelve cases were prepared for research through the collection of quantitative measures from standardized scales. We could see that the participants rated the alliance to be 
fairly good (WAI; Hatcher \& Gillapsy, 2006; Horvath, 1994a, 1994b; Horvath \& Greenberg, 1989). Ratings also suggested a positive development in all cases (OQ64; Lambert \& Burlingame, 2004 and IIP-C; Horowitz, Rosenberg, Baer, Ureño, \& Villaseñor, 1988) and the clients diagnostically represent a common outpatient clientele as diagnosed by SCID interview (First, Spitzer, Gibbon, Williams, \& Benjamin 1995; 1997).

All therapy sessions were audio-recorded, which gave the opportunity to observe the dialog of the therapy sessions chronologically. After every session the clients and therapists separately wrote a small reflective note in which they answered the question: "What was the most important aspect of this session and why?” These notes gave an experience-based description of what occurred in the sessions. After the end of therapy, both clients and therapists were interviewed about their experiences and reflections on the therapy. The interview guide was organized around the therapeutic process and helpful as well as challenging aspects of treatment. The data collection procedures are part of the larger research project (Rønnestad, 2006) and independent of the data analysis in this paper.

\section{Researchers}

All authors are psychologists and experienced psychotherapists and all combine practicing and teaching psychotherapy with research.

\section{Ethics}

This study was approved by the Regional Committee for Medical and Health Research Ethics (Region South-East) and by Norwegian Social Science Data Services (Rønnestad, 2006). Informed consent has been given and details of the participants have been changed to provide anonymity. 


\section{Analyzing interactions and reflections}

A hermeneutic-phenomenological approach was chosen (Finlay, 2003; Gadamer, 1989; Heidegger, 1962; Laverty, 2003; McLeod, 2011; Smith, 2007; Smith \& Osborn, 2003). The hermeneutical element implies that interpretation is a necessary and unavoidable act when we attempt to understand and point out the meaning of the clients' and therapists' utterances. The phenomenological element implies a commitment to understanding the concrete lived experiences of the participants (van Manen, 1990; Smith, Flowers \& Larkin, 2009). We argue that new understanding is achievable only through a "fusion of horizons" between the researchers' and the participants' experience (Gadamer, 1989; Laverty, 2003; Smith, 2007).

The selection of relevant material was performed with the use of a hermeneutically modified method for systematic text condensation (Malterud, 1993, 2001) and inspired by McLeod \& Balamoutsou's (2001) qualitative narrative analysis of psychotherapy transcripts. The text condensation has similarities with the defining of "meaning units" to discern the psychological essence in phenomenological analysis (Giorgi \& Giorgi, 2003). The analysis was carried out with the assistance of Nvivo 8 software (QSR, 2008). The data analysis proceeded along the following steps. (i) The first author listened to and transcribed verbatim the recordings of the interviews and strategically selected therapy sessions. Every last session was transcribed first. To search for further sessions where ending was a theme, we used information gathered from the interviews, the notes informants made after every session, and the already transcribed last sessions. These additional sessions were carefully assessed and dialogs about ending, in the broadest sense, were transcribed. (ii). Thereafter, the first author went through the material anew and thoroughly selected statements and dialog focusing on improvement and change. (iii) All the authors read through the written material, and the focus on improvement made us realize the richness of the metaphors used to describe change in the 
context of approaching an end. (iv) The next step was, therefore, to sort out these metaphors. (v) The first author discussed the material alternately with the second and third author and we discussed the meanings of the metaphors and the ways they were used. Our knowledge of the broader material helped contextualize and understand the metaphors. (vi) Eventually, we refined the guiding questions in order to reach a procedure that could be used in a systematic way to cover all cases. Categories of metaphors were selected through dialog with the material and dialog between the researchers. The categories were refined and compressed to the presented configuration of findings. (vii) Examples and quotes were chosen to illustrate the various metaphors. We have included thick descriptions (Denzin, 1989; Geertz, 1973), a presentation style that provides the reader with quotes exemplifying the meaning of our findings, and enhances the transparency of our interpretative process.

\section{Findings}

The dialogs about therapeutic improvement in the context of ending psychotherapy are packed with metaphors. The metaphors clients and therapists create together and use toward the end of therapy seem to capture the consolidation of accomplishments they have reached, optimism facing life after therapy, and the reality of confronting new challenges in life.

Changes that brought me further - travel metaphors

Across the material, life as a journey and therapy as a time-limited joint travel, are widely used images. This also accounts for the dialog about therapeutic improvement in the context of approaching an end. As one client described in the interview: 
"I feel like I moved further in my life. Still, from time to time I experience episodes where it feels like the world is falling apart. I still have struggles, but now I am more able to move on... I probably have a distance left to go, but now I've got tools to use, I have something to tell myself when situations are difficult”.

The therapist used similar travel imagery when explaining in the interview that her client now "is in a totally different place".

The travel metaphors can also be about standing still or losing one's way for a while, but finding a way to move on. As these clients remarked:

"When you get lost in a tangle of depressive thoughts, it takes time before you are able to find your way on your own. She helped me to see it and to get on track again”.

"For periods during the therapy process I felt like we stood still, that we didn't come any further. But then, all of a sudden it released again, and then we made jumps forward”.

Obstacles in life can be seen as brakes which delay travel, as this dialog shows: Therapist: Earlier your back pain was a brake for you, and your mother and her illness was a brake. Both factors are less of a brake for you now.

Client: That's true.

Therapist: And now when you don't have kids at home anymore, you are really in a situation where you can use your time and take the steps forward.

One therapist talked in the interview about the importance of bringing therapy to an end as soon as the client was able to walk the rest of the distance on her own:

“One shouldn't use therapy to resolve all one's troubles; she shall go on with her life. The therapist shall only walk part of the distance". 
In their dialogs about ending, this therapeutic dyad talked about therapy as fellow travelers and life as a journey, as this excerpt from their last session together demonstrates: Client: Actually, I think it's good timing. I feel ready now. I feel much calmer now, I feel safer. I know there will be fluctuations...

Therapist: Yes, but what counts is the way it fluctuates: if you think of yourself as someone who suffers from some awful illness, or if it is because you just go on with your life and take the ups and downs just like everybody. You just said that this last year has been a year of progress; even if there have been obstacles along the road. I think of it just the same way. My experience is that you have consolidated your growth very powerfully, that you have dared to live your life, and also tolerated some of the hard parts.

Client: Yes, that's how I feel. Especially that last downturn I had, that scared me so, I thought now everything unravels; now it happens again. So, that I managed to get back on track, and I understood what I needed to do ...

Therapist: I think of my role as a fellow traveler in one stage of your journey. But the journey is yours, and it lasts for a lifetime.

Client: So I have to have other fellow travelers.

Therapist: Yes, you have other fellow travelers.

Client: Yes, all in all I'm very content; I have walked a long distance.

Confronting the end of therapy also stirs up feelings of fear and hesitation. The metaphor of life as an uphill and downhill journey seems to be constructed and used to prepare the client to deal with obstacles along the road after therapy has come to an end.

Changes that brought an end to the mess - Clean up metaphors 
In our material metaphors expressing change in therapy through cleaning up or sorting out issues are widely used. A common phrase is that pieces have been arranged into place. There were other ways to express this: "I feel loose ends have been tied"; "We managed to get things into their right place"; and "I have learned to unravel the tangles".

The clean up metaphors seem basically to be about leaving something behind that is meant to come to an end.One client, a 50 year old woman,had to deal with an extremely painful life experience. She sought therapy after she lost her teenage son to suicide. Foremost, improvement in this case consisted of finding ways to deal with grief. In the interview the clientdescribes her healing process as a process of cleaning out a chest: "As if it is a drawer. You have many drawers with experiences, and as you walk, you are able to close the drawers. But that drawer I can never close, it will always stand open. And when I started therapy it was just chaos in it. Everything is still there, but it is tidied up and stacked in piles and systematized. I got help with the cleaning. That drawer is not as scary as it was. Earlier I dreaded to look, I was afraid, but now I can relate to it. And I know that every time one of these themes is brought up, I feel I have already been through them, that they are as manageable as they can ever become and I am able to finish it faster. I am not afraid of a glance in that drawer. Only it is very, very sad."

Her therapist describes her development in a similar and complementary way: "She had a notion that she could put all her grief in a drawer, almost like filing, and so she should have bits of grief in various drawers. I think that came out in a somewhat different way for her. She saw that very clearly, that she couldn't put it away; she had to live with it."

The metaphor this clientused, about arranging problems in a chest of drawers, which is outside herself, can be thought of as a kind of externalisation. Through metaphorical 
externalisation she seemed to be able to emotionally integrate almost unbearable issues. This therapeutic dyad shared several vivid metaphors in the dialog and the metaphors they used were active parts of the interaction between them.

Changes in the way I sense

Metaphors about growing stronger, standing on one’s own feet or finding balance are widely used. Existential issues appear as kinesthetic or visual perceptions. As one client told her therapist in their last session together:

"I feel like I have got a new strength inside, like I stand steadier. I am not so afraid of what people might think of me, as I was before, and not so afraid of receiving criticism. I have grown stronger; I don't need to be pleasing people all the time”. This client sought therapy because of severe anxiety and compulsively telephoning fortune tellers, a habit that resulted in debt problems. She felt that she had no control. The client and her therapist talk about improvement as a process, in which the client has grown stronger. (Interview) Client: Now I feel much stronger than I have ever been.

(Interview) Therapist: Her most important goal was to find her inner strength, to have faith in herself, and she feels like she has reached that.

In their last session together, they talked about the client's improvement in terms of having grown stronger.

Therapist: ...Yes, and your strength?

Client: That I have grown stronger?

Therapist: Yes.

Client: I feel that I have gained control over myself and I feel much stronger.

Therapist: So now, after having become stronger, you feel you have a reason to be braver. 
The different clients' continuous will and ability to challenge themselves seem to be important outcome throughout the material.

Another way of sensing is to see things more clearly, or from new perspectives, as described by a therapist in the interview:

"There were some important sessions where we got new perspectives on the here and now situation."

In the last session of his therapy, his client sums it up like this:

"If it continues like this life looks bright. I am sure I can develop further, that I can become better to see things, and that is something I want to continue to work on. But I have got a totally new picture of life, it looks different”.

A new light can also make sight clearer, as one client stated:

"She put a different light on the issues I had struggled with for so long, and then I became able to discover it myself."

Therapy helped me get in a better position

Metaphors that point toward changes in bodily position or status were also common in the material. These metaphors all imply feelings of freedom, being balanced, and having acquired increased possibilities for movement. They appear to point toward experiences of being able to handle life after therapy more effectively, to move on, and, in some sense, to achieve more autonomy.

These metaphors are about keeping one’s head above water:

"As I have got my head above water, I do not need to stand on tiptoe so as not to drown".

of feeling less heavy: 
“I don't feel like I am a burden anymore. My problems are of a much easier character. Now I don't feel like I am a burden when I talk with my friends about my troubles. But for a period, I felt so heavy”.

and of having achieved more freedom to move:

“I don't feel like I am imprisoned, like I felt before”.

This sense of acquired freedom is clearly expressed in this last session:

Therapist: And now you have dared to completely breake up with Joe, and you feel calmer.

Client: Yes, I do! I feel really much calmer. It feels like freedom!

Therapist: Like freedom!

Client: Yes, I feel free! It's such a relief. I am so finished with him.

Therapist: It is interesting that you talk about it this way. I looked in my notes, and read what you wanted to achieve when we started, and the word you used when you talked about Joe was prison.

Client: Did I? Really?

Therapist: Yes. And now you use the word freedom!

Client: Yes. I felt as if in a prison, that I was somewhat imprisoned, that I couldn't come out. And now I'm free.

Receiving something that opened new possibilities - gifts, tools, and keys

Several of the clients talk about feeling as if they have received a gift from the therapist. In one interview the client remarked:

"It has been a gift for me this therapy. Now I feel grateful and curious about my own biography, and I feel it has become a material I can use”.

Some of the clients talked about these gifts as tools they could use in the future, as this client remarked: 
“I probably have a distance left to go, but now I've got tools to use, I have something to tell myself when situations grow difficult”.

A variant of the gift metaphor is used by this client, who said in the interview that she felt the therapist had found a key and given it to her:

"One distinctive moment was when the therapist found a key, a very, very important key. It was a parallel story from a book. And that was the key. Suddenly I saw it very clearly. It was about finding that key. Many pieces fell into places; I saw it in a totally new way. He freed me from playing that role”.

This metaphor contained multi-layered meaning, and in the session when it was introduced, the client and therapist seemed to grow closer and more equal by sharing basic human experiences, as well as interest in literature. For the client, the literary reference was experienced as a key, which opened up a new understanding of various themes in her life. It gave her a new perspective on her roles and responsibilities within her family, as well as on the dilemmas she was struggling with in a previous psychotic episode. It also gave her the ultimate proof of engagement and empathy from the therapist, and contributed to her own self-understanding and change in the approach to her own mission in life. This metaphor has been more thoroughly elaborated in a single case analysis (anonymous reference).

Other tools could be warning lights, as this client noted:

“Now, when I am very strict toward myself, warning lights come up, that sort of say:

'Now you did that to yourself again'. I have become aware of it so I can relate differently to myself now”.

Similarly, another dyad developed a metaphor of a warning sign in their last session together:

Client: The only thing I fear is that about fortune-tellers, that I should be trapped in that again. Perhaps I'm like an alcoholic on that, which I have to learn to... 
Therapist: That you need to be totally abstinent. Or... perhaps you could use a warning sign? So you can warn yourself and not walk into that minefield?

Client: Yes.

Therapist: Yes, something saying: 'This is a minefield. Stop! Don't go any further, a kind of one-way sign or stop sign. A stop sign, maybe?’

Client: Yes, I have managed to stop myself sometimes; I have called a friend instead.

\section{Discussion}

When the language of therapeutic improvement becomes full of metaphors describing growth in affective and relational management, this seems to address feelings in a way that is intensely felt and shared without necessarily being explicitly examined. The metaphors we found in the dialogs and afterthoughts about improvement in the context of approaching an end could be arranged into these categories:

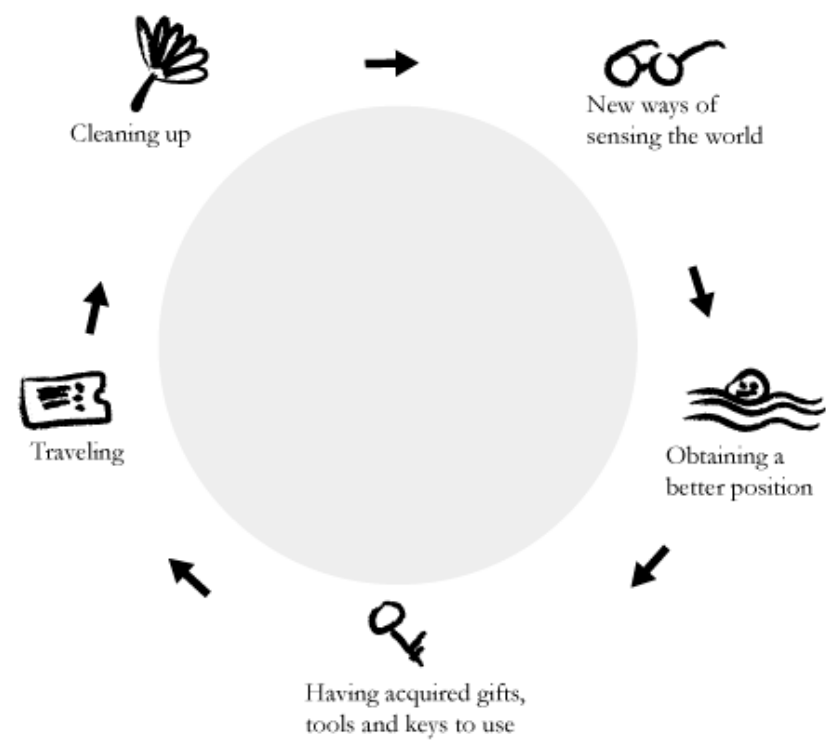


- Traveling

- Cleaning up

- New ways of sensing the world

- Obtaining a better position

- Having acquired gifts, tools, and keys to use

These categories of metaphors are still internally connected in the sense that they depict existential issues and a change that is worth noticing and celebrating. If life is a journey, a series of experiences, being able to see clearly and to move freely, avoiding stumbling in tangles, and possessing keys and tools to deal with obstacles along the road would be important and useful. Such metaphors convey implicitly and convincingly that therapy mirrors life and life mirrors therapy.

What is it that distinguishes the metaphors which turned out to be useful in the therapeutic communication toward the end? In our material the metaphor stemmed from either the client or the therapist, but when it worked well it seemed to take on significant cocreated meaning in the relationship. Using a metaphor can be a way of looking at something together and trying out ideas in a somewhat playful way. The metaphors may also keep distant difficult matters and, at the same time, provide an opportunity to deal with trauma and to integrate new experiences. They can be a way, therefore, of dealing with the possible fear of upcoming separation. This is in line with earlier research, which suggests that it is not the uses of metaphor by the client in psychotherapy that is the important factor determining its productive potential; neither who created it nor whether it is novel or clichéd (Angus \& Rennie, 1988). Rather, it seems to be the ambiguous character of who created the metaphor and for what purposes that opens up opportunity for the integration of new and in this sense 
unknown experiences. One may say that the metaphor works as a sort of transitional object for the client in leaving the therapist, and for the therapist in letting go (Winnicott, 1971).

The creation and use of metaphors in therapy can be a symbol of continuation of the relationship after therapy has come to an end. They have created a tailor-made language together. In close relationships, such as love, people commonly develop an idiosyncratic shared language with common references. This phenomenon probably adds to closeness in the relationship. In psychotherapy relationships the tailor-made language may symbolize the unique therapeutic relationship, and it lasts beyond the sessions. The clients have something with them to use as, for example, a key, a tool or a piece of furniture, which signify ways of mastering difficulties and solving problems, and give meaning to the experience of having acquired ways of working that can be used after the therapy has ended.

On a more figurative level, the concepts used to make the different metaphors we found in these therapies all describe ways of positioning and using the body in the world. Taken as embodied experiences, changes equal movements, sensing, and bodily capacities including handling objects, in line with Lakoff and Johnson's (1980) theory of the origin of metaphors. This is also possible to understand in light of Greenberg's (2006) conceptualisation of the “emotional scheme” and Damasio’s (1999) theory of the role of bodily sensations and primary bodily awareness in the experience of emotion. Emotion can be seen as a primary source of information about a person's needs and relationships with both self and others, which gives direction to actions (Tomkins, 2008).

On an existential level, “moods” can be viewed as entries into a primary knowing of how one "befinds" oneself in the world (Heidegger, 1962). In metaphors the language of the body and the language of relationships intersect, and, as we find in our study, provide ways to express, work with and transform difficult life experiences through collaborative psychotherapeutic relationships. Through the metaphors of travel and change in one’s 
position, feelings associated with encountering something new and achieving new goals can be expressed. Such expressions will also activate the contrasting state when movement is lacking, and the relief that follows from escaping feelings of stagnation. A sense of being stronger may imply a feeling of courage, and thus being able to experience difficult circumstances as they are, and being able to do something to change them.

Cleaning up seems to express achieving a sense of well-being, and organizing the sad memories of past events in ways that allow for new engagements in life. Achieving gifts, tools, and keys may point toward feelings of mastery, and, in some instances, gratitude toward the therapist. All of these associations between embodied experiences and emotional states capture core emotional, relational, and existential themes in these clients' therapies, and point toward the possibility of progress.

Levitt, Korman, and Angus (2001) describe how transformations in the "burden" metaphor in psychotherapy of depression signify symptomatic and experiential changes. In our study, metaphor opened up ways to give meaning to the problem examined in therapy, the tools for solving it, and its solution. Further explorations of how participants in psychotherapy create metaphors to express their experience of change processes can add to our understanding of what constitutes good psychotherapy outcome.

\section{Limitations}

One difficulty has been to translate the metaphors from Norwegian to English. Metaphors are contingent on shared cultural as well as linguistic understanding , and translating them occasionally interferes with meaning. However, surprisingly many of the metaphors could meaningfully be translated. We think that the categorization of the metaphors conveys how they are used in the service of managing a "good enough" ending. Our starting point was the ways in which the process of ending was packed with metaphors. 
In analyzing what the metaphors do, we moved beyond what can be directly observed and explicitly reported. The case-by-case interpretations rely on theoretically informed analyses of the empirical material. Still, the striking parallels in a series of cases help to validate these results.

\section{Implications for practice}

The joint creation of metaphors used to represent what is accomplished during therapy as a way to move toward the end seems to happen spontaneously and not according to a plan. The point here is not to make recommendations for the use, for instance, of particularly suitable metaphors, but rather to address this creative spontaneity and the emotional qualities of creating them together in a way that makes them unique. The positive emotional states emerge in a convincing way just because they are different from and will negate or counterbalance the implicit danger of feeling stagnation and loneliness. As figure 1 illustrates, the possible material to create metaphors for change as accomplished through dialogs are everywhere. Still, such material will have to be captured and developed in dialogs in order to establish a unique sense of shared emotional meaning. The metaphors are not denying a difficult past, but work to include it in the present in ways that can be shared and handled. The narrative form in this article will hopefully be viewed by clinicians as recognizable and, potentially, as having transfer value to enrich their methods of practice when similar situations occur. The lessons that are expressed in the metaphors - for therapist as well as client - seem to be that the client is better equipped for handling the emotional qualities of upcoming difficulties, and not protected from difficulties as such. The metaphors point to the possibility that the relationship between them will continue to exist as a working model for the future. On the part of the client, it is about living a life, and on the part of the therapist, it is about working with new clients. 


\section{References}

Alvesson, M. \& Sköldberg, K. (2000). Reflexive methodology. New vistas for qualitative research. Los Angeles: Sage.

Angus, L.E. (1996). An intensive analysis of metaphor themes in psychotherapy. In J.S. Mio \& A. Katz (Eds.), Metaphor: Pragmatics and Applications. New York: Erlbaum.

Angus, L.E. \& Rennie, D.L. (1988). Therapist participation in metaphor generation, collaborative and noncollaborative styles, Psychotherapy, 25, 552-560.

Angus, L.E. \& Rennie, D.L. (1989). Envisioning the representational world: the client's experience of metaphoric expressiveness in psychotherapy. Psychotherapy, 26, 373379.

Bruner, J. (1985). Actual minds, possible worlds. Cambridge, MA: Harvard University Press.

Bruner, J. (1990). Acts of meaning. Cambridge, MA: Harvard University Press.

Denzin, N.K. (1989). Interpretive interactionism. Newbury Park: Sage.

Damasio, A.R. (1999). The feeling of what happens: body and emotion in the making of consciousness. New York : Harcourt Brace.

Finlay, L. (2003). Through the looking glass: intersubjectivity and hermeneutic reflection. In L. Finlay, \& B. Gough (Eds.), Reflexivity. A practical guide for researchers in health and social sciences. Oxford: Blackwell.

First, M. B., Spitzer, R. L., Gibbon, M., Williams, J. B. W., \& Benjamin, L. (1995). User's guide for the Structured Clinical Interview for DSM-IV Axis II Disorders (SCID-II), (Version 2.0). Unpublished manuscript, Biometrics Research Department, New York State Psychiatric Institute. 
First, M.B., Spitzer, R.L., Gibbon, M., Williams, J.B.W., \& Benjamin, L. (1997). Structural clinical interview for DSM-IV axis II disorders. New York: Biometrics Research Department.

Gabbard, G. O. (2009). What is a "good enough" termination? Journal of the American Psychoanalytic Association, 57, 575-594.

Gadamer, H.G. (1989). Truth and Method. London: Continuum.

Geertz, C. (1973). The interpretation of cultures. New York: Basic Books.

Giorgi, A. \& Giorgi, B.M. (2003). The descriptive phenomenological psychological method. In P.M. Camic, J.E. Rhodes \& L. Yardley (Eds.), Qualitative research in psychology: Expanding perspectives in methodology and design (pp. 243-274). Washington DC: American Psychological Association.

Goncalves, Ó.F., Henriques, M.R. \& Machado, P.P.P. (2004). In. L.E. Angus \& J. McLeod (Eds.) The handbook of narrative and psychotherapy. Practice, theory, and research. London: SAGE

Greenberg, L. S. \& Watson, J. C. (2006). Emotion-focused therapy for depression. Washington, D.C: American Psychological Association.

Heidegger, (1962). Being and time. Oxford: Blackwell.

Hatcher, R.L., \& Gillapsy, J.A. (2006). Development and validation of a revised short version of the Working Alliance Inventory. Psychotherapy Research, 16, 12-25.

Hoffman, I. Z. (1998). Constructing good-enough endings in psychoanalysis. In I.Z. Hoffman (Ed.), Ritual and spontaneity in the psychoanalytic process. A dialecticalconstructive view (pp. 245-273). Hillsdale, NJ: Analytic Press.

Holmes, J. (2010). Termination in psychoanalytic psychotherapy: an attachment perspective. In J. Salberg (Ed.) Good enough endings. Breaks, interruptions, and terminations from contemporary relational perspectives (pp. 63-82). New York: Routledge. 
Horowitz, L.M., Rosenberg, S.E., Baer, B.A., Ureño, G., \& Villaseñor, V.S. (1988).

Inventory of interpersonal problems: Psychometric properties and clinical applications. Journal of Consulting and Clinical Psychology, 56, 885-892.

Horvath, A.O. (1994a). Empirical validation of Bordin’s pantheoretical model of the alliance: The Working Alliance Inventory perspective. In A.O. Horvath \& L.S. Greenberg (Eds), The working alliance: Theory, research and practice (pp. 109-128). New York: Wiley. Horvath, A.O. (1994b). Research on the alliance. In A.O. Horvath \& L.S. Greenberg (Eds), The working alliance: Theory, research and practice (pp. 259-286). New York: Wiley. Horvath, A.O. \& Greenberg, L.S. (1989). Development and validation of the Working Alliance Inventory. Journal of Counselling Psychology, 36, 223-233.

Hynan, D.J. (1990). Client reasons and experiences in treatment that influence termination of psychotherapy. Journal of Clinical Psychology, 46, 891-895.

Lakoff, G. \& Johnson, M. (1980). Metaphors we live by. Chicago: The University of Chicago Press.

Lambert, M. \& Burlingame, G.M. (2004). Administration and scoring manual Outcome Questionnaire (OQ 45.2). Salt Lake City: American Professional Credentialing Services L.L.C.

Laverty, S. M. (2003). Hermeneutic phenomenology and phenomenology: A comparison of historical and methodological considerations. International Journal of Qualitative Methods, 2, 21-35.

Levitt, H., Korman, Y., \& Angus, L. (2001). A metaphor analysis in treatments of depression: metaphor as a marker of change. Counselling Psychology Quarterly, 13, 23-35.

Malterud, K. (1993). Shared understanding of the qualitative research process - Guidelines for the medical researcher. Family Practice, 10, 201-206.

Malterud, K. (2001). Qualitative research: standards, challenges, and guidelines. The Lancet, 
358, 483-488.

McMullen, L. (1985). Methods for studying the use of novel figurative language in psychotherapy. Psychotherapy, 22, 610-619.

McMullen, L. (1989) Use of figurative language in successful and unsuccessful cases of psychotherapy: three comparisons. Metaphor and Symbolic Activity, 4, 203-225.

McLeod, J. (2011). Qualitative research in counselling and psychotherapy. London: Sage.

Muran, J.C., Safran, J.D., \& Eubanks-Carter, C. (2010). Developing therapist abilities to negotiate alliance ruptures. In. J.C. Muran \& J.P. Barber (Eds.), The therapeutic alliance. An evidence-based guide to practice (pp. 320-340). New York: The Guilford Press.

QSR (2008). Nvivo 8. Doncaster, QSR: International Pty Ltd, Victoria, Australia.

Rasmusen, B. \& Angus, L.E. (1996). Metaphor in psychodynamic psychotherapy with borderline and non-borderline clients: a qualitative analysis. Psychotherapy, 33, 521530.

Rønnestad, M.H. (2006). An intensive process-outcome study of the interpersonal aspects of psychotherapy. Oslo: University of Oslo, Department of Psychology.

Salberg, J. (Ed.) (2010). Good enough endings. Breaks, interruptions, and terminations from contemporary relational perspectives. New York, NY: Routledge.

Schlesinger, H. J. (2005). Endings and beginnings: On the technique of terminating psychotherapy and psychoanalysis. Hillsdale, NJ: Analytic Press.

Shane, E. (2009). Approaching termination: Ideal criteria versus working realities. Psychoanalytic Inquiry, 29, 167-173.

Smith, J.A. (2007). Hermeneutics, human sciences and health: linking theory and practice. International Journal of Qualitative Studies on Health and Well-being, 2, 3-11. 
Smith, J.A., Flowers, P., \& Larkin, M. (2009). Interpretative phenomenological analysis. Theory, method and research. London: Sage.

Smith, J.A., \& Osborn, M. (2003). Interpretive phenomenological analysis. In J.A. Smith (Ed.) Qualitative psychology. A practical guide to research methods (pp. 9-26). London: Sage.

Tomkins, S.S. (2008) Affect imagery consciousness: the complete edition. New York: Springer Publications.

van Manen, M. (1990). Researching lived experience: Human science for an action sensitive pedagogy. Ontario: The University of Western Ontario.

Winnicott, D.W. (1971) Playing and reality. London: Routledge. 